\title{
SIMULTANEOUS ELECTROCHEMICAL DETECTION OF DOPAMINE, ASCORBIC ACID AND URIC ACID US- ING COPPER-PHTHALOCYANINE FUNCTIONALIZED MWCNTS
}

\author{
MAMIE SANCY, J. FRANCISCO SILVA, JORGE PAVEZ AND JOSÉ H. ZAGAL* \\ Departamento de Química de los Materiales, Facultad de Química y Biología, Universidad de Santiago de Chile, Casilla 40, Correo 33, \\ Sucursal Matucana, Santiago 917009, Chile \\ (Received: August 8, 2013 - Accepted: November 27, 2013)
}

\begin{abstract}
Multiwalled carbon nanotububes functionalized with amino groups (MWCNT- $\mathrm{NH}_{2}$ and further modified with copper-phthalocyaninetetrasulphonate (4 $3\left(\mathrm{SO}_{3}\right)$ $\mathrm{CuPc}$ ) were used for preparing a hybrid electrode [MWCNT-NH$/ 4 \beta\left(\mathrm{SO}_{3}\right) \mathrm{CuPc} / \mathrm{GC}$ ] using glassy carbon $(\mathrm{GC})$ as a support. This hybrid electrode was tested for the detection of dopamine (DA) in the presence of ascorbic acid (AA) and uric acid (UA) in a PBS buffer solution at pH 6.8. The presence of the macrocyclic increased the resolution of the oxidation signals of AA, DA and UA into three very well distinct oxidation peaks. This effect was enhanced when the complex is adsorbed on multiwalled carbon nanotubes. In addition, the hybrid films provide a simple method for selective detection of DA, AA and UA in biological samples. The calibration curves for DA were obtained over the range of $1 \times 10^{-6}-1 \times 10^{-3} \mathrm{M}$, obtaining a good selectivity and sensitivity
\end{abstract}

Keywords: Dopamine, ascorbic acid, uric acid, carbon nanotubes, copper-tetrasulphonate phthalocyanine, hybrids electrodes, sensor, modified electrodes.

\section{INTRODUCTION}

Dopamine (DA) is an important neurotransmitter that plays a significant role in the functioning of the central nervous, renal and hormonal systems ${ }^{1,2}$. Exocytotoxic malfunction is involved in several neurodegenerative disorders such as Parkinson's and Alzheimer's diseases, where the dopaminergic activity is lower than in healthy individuals. The opposite is true in schizophrenia where the activity of the dopaminergic neurons is increased due to abnormalities in their regulation ${ }^{3-5}$. The development of anorexia nervosa and bulimia nervosa has also been associated with altered dopaminergic activities. For these reasons the development of electrochemical sensors for the determination of neurotransmitters has received great attention in the past ${ }^{6}$. During 2012 and 2013 the projects for mapping brain activity and brain research through advancing innovative neurotechnologies were consolidated, and the latter was highlighted by the scientific community, as the "next great American project". The challenge involves working with multiple neurotransmitters simultaneously, in contrast with classical neuropathology, which was centered on the activity of a group of neurons and a single neurotransmitter. This requires understanding the complexity of the brain and its interconnectivity. In detection of neurotransmitter DA is electrochemical active on some electrode surfaces, via its oxidation, so the design of active electrodes for dopamine detection has received a great interest in electroanalysis ${ }^{7-9}$. Unfortunately, ascorbic acid (AA) and uric acid (UA) are always coexisting with DA in living organisms, sharing a similar oxidation potential so they interfere with the electrochemical detection of DA. As a result, the accuracy of its determination is remarkably low in real samples ${ }^{10}$. However, DA, AA and UA are of great biomedical interest and play an important role in human metabolism ${ }^{11,12}$, so it is impossible to avoid their presence in real samples. The basal DA concentration is very low $(0.01-1 \mu \mathrm{M})$, while the concentration of AA and UA is generally much higher than that of DA (from 100 to 1000 times higher), thus, it is extremely important to develop sensitive and selective methods for the determination of DA in routine analysis ${ }^{13-15}$ without the problem of interferents. Electrodes modified with Nafion $^{16}$, conducting polymers ${ }^{17}$, and ion-exchange membrane electrodes ${ }^{18}$, molecular imprinted polymer ${ }^{19,20}$, metal nanoparticles ${ }^{15,21,22}$, carbon nanotubes films (CNT), are excellent electrode materials ${ }^{23}$ for potential applications in electroanalysis due to their unique structure, good electrical conductivity and mechanical stability. Various CNT-modified electrodes have been used for the simultaneous detection of DA, UA and $\mathrm{AA}^{24}$. However, these electrodes are problematic due to the longer response-time, poor long term stability and limited sensitivity. Recently, metallo-phthalocyanines, which are well-known for their electrocatalytic activity ${ }^{25-30}$ for many ET reactions have been used in neurotransmitters sensors. For example, it has been suggested that a complex between DA and iron phthalocyanine ( $\mathrm{FePc})$ is formed and involving internal electron transfer ${ }^{25}$. Kang et al. ${ }^{26}$ have used a nickel-phthalocyanine modified $(\mathrm{NiPc})$ electrode as DA sensor in electrochemical measurements, where an electrocatalytic effect was observed for the oxidation of DA and attributed to the presence of NiPc. Because sensing properties of organic materials are usually enhanced when nanostructured films are employed the fabrication of phthalocyanine ultrathin films has been pursued by a number of groups $s^{27,31,32}$ Therefore, in this manuscript we report the development of a simple and lowcost amperometric sensor, based on a copper phthalocyanine, for the detection of DA in the presence of AA y UA.

\section{EXPERIMENTAL}

\subsection{Reagents and solutions}

Copper tetrasulphonate phthalocyanine $\left(4 \beta\left(\mathrm{SO}_{3}\right) \mathrm{CuPc}\right)$ was obtained from Aldrich (U.S.A.). Multi Walled Carbon Nanotubes functionalised with- $\mathrm{NH}_{2}$ groups (MWCNT- $\mathrm{NH}_{2}$ ) and presenting a $0.5 \%$ of $-\mathrm{NH}_{2}$ functionalization were obtained from Dropsens (Spain). The average diameter was around $10 \mathrm{~nm}$ and the average length was 1-2 $\mu \mathrm{m}$. DA, AA and UA were purchased from SigmaAldrich (U.S.A.) and used without further purification. Phosphate buffer solutions (PBS) were prepared by mixing a $0.1 \mathrm{M} \mathrm{K}_{2} \mathrm{HPO}_{4}$ and $0.1 \mathrm{M} \mathrm{KH}_{2} \mathrm{PO}_{4}$. Double-distilled water was used to prepare all solutions. All experiments were performed at $20^{\circ} \mathrm{C}$.

\subsection{Instruments and apparatus}

Cyclic voltammetry measurements were performed using an Autolab Potentiostat/Galvanostat PGSTAT 30 connected to a PC. Electrochemical measurements were performed in an electrochemical cell containing a platinum wire of $5 \mathrm{~cm}^{2}$ as auxiliary electrode, a silver/silver chloride electrode $(\mathrm{Ag} / \mathrm{AgCl}$ saturated with $\mathrm{KCl}$ ) as reference and a glassy carbon disk mounted in Teflon with $0.44 \mathrm{~cm}^{2}$ (Pine Instruments, U.S.A.) as working electrode (GC). AFM images were obtained with a Nanoscope IIIa Multimode microscope (Digital Instruments, Santa Barbara CA) using commercial $\mathrm{Si}_{3} \mathrm{~N}_{4}$ cantilevers from Digital Instruments, Santa Barbara CA.

\subsection{Preparation of the modified electrodes}

Before surface modification, the GC electrodes were mechanically polished with 800 and 1200 silicon carbide paper (Struers, Denmark) until a regular surface was obtained followed by ultrasonic cleaning in purified water for 30 seconds. MWCNT-NH $\mathrm{N}_{2}$ dispersions were obtained using $0.5 \mathrm{mg}$ of crude MWCNT- $\mathrm{NH}_{2}$ that were dispersed in $1.0 \mathrm{~mL}$ DMF using ultrasonic stirring for 6 hours. Modification of the MWCNTs with $4 \beta\left(\mathrm{SO}_{3}\right) \mathrm{CuPc}$ was achieved by treating $0.5 \mathrm{mg}$ of MWCNT-NH $\mathrm{H}_{2}$ and $0.5 \mathrm{mg}$ of $4 \beta\left(\mathrm{SO}_{3}\right) \mathrm{CuPc}$ (Sigma-Aldrich) in $0.5 \mathrm{~mL} \mathrm{DMF}$ and $0.5 \mathrm{~mL} \mathrm{H} \mathrm{H}_{2} \mathrm{O}$. The mixture was stirred with ultrasound for 6 hours. A $20 \mu \mathrm{L}$ aliquot of the dispersion was placed as a droplet on the GC electrode surface and the solvent was then left to evaporate at $60^{\circ} \mathrm{C}$ for $20 \mathrm{~min}$. The response of the modified electrode obtained in this fashion was tested as an electrochemical sensor as described in the Discussion.

\section{RESULTS AND DISCUSSION}

\subsection{GC modified electrodes}

Figure 1 illustrates a series of cyclic voltammograms obtained with the unmodified and modified electrode using different treatments and in the presen- 
ce of the electrolyte only. Bare $\mathrm{GC}$ and $\mathrm{GC} /\left(4 \beta\left(\mathrm{SO}_{3}\right) \mathrm{CuPc}\right)$ electrodes show practically the same response whereas the GC/MWCNT-NH ${ }_{2} /\left(4 \beta\left(\mathrm{SO}_{3}\right) \mathrm{CuPc}\right)$ shows some anodic and cathodic currents at potentials close to the extreme potentials of the range examined. There are no peak currents in the potential region examined. The cyclic voltammograms at the bottom of Fig. 1 show an amplification of the anodic region. The Figure on the left compares the response of the bare $\mathrm{GC}$ and $\mathrm{GC} / 4 \beta\left(\mathrm{SO}_{3}\right) \mathrm{CuPc}$. The presence of $4 \beta\left(\mathrm{SO}_{3}\right) \mathrm{CuPc}$ increases the current response in this region, since the bare GC practically shows no currents in this region. GC shows currents only at more positive potentials (beyond 0.8 V) that are due to the oxidation of the carbon. The Figure on the bottom right compares the response of $\mathrm{GC}$ with $\mathrm{GC} / \mathrm{MWCNT} / 4 \beta\left(\mathrm{SO}_{3}\right) \mathrm{CuPc}$. The presence of the carbon nanotubes increases the response of the electrode, there is no current peak but the foot of a wave is clearly visible and seems to correspond to an oxidation process associated to the $4 \beta\left(\mathrm{SO}_{3}\right) \mathrm{CuPc}$ that is enhanced by the presence of the MWCNT since in this case probably more phthalocyanine molecules are present by unit of geometric area as a result of an increase of the roughness factor of the electrode coated with carbon nanotubes ${ }^{33}$.

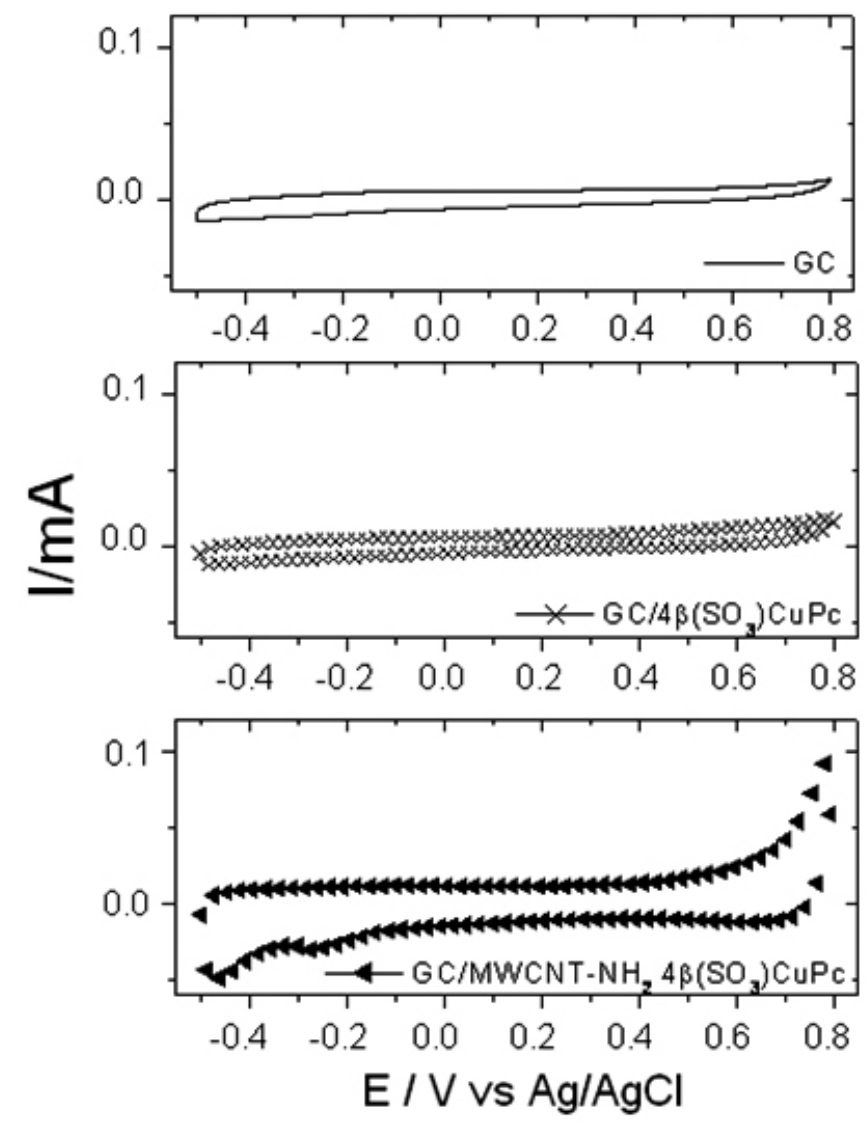

Figure 1: Cyclic voltammograms of GC electrode modified with $4 \beta\left(\mathrm{SO}_{3}\right)$ $\mathrm{CuPc}$ functionalized with MWCNTs. All solutions were prepared in a $0.1 \mathrm{M}$ PBS buffer with pHadjusted to 6.8 . Scan rate $=0.2 \mathrm{Vs}^{-1}$ and the scanning started at -0.5 to $0.8 \mathrm{~V}$ vs. $\mathrm{Ag} / \mathrm{AgCl}$. (-) $\mathrm{GC},(-\mathrm{x}-) \mathrm{GC} / 4 \beta\left(\mathrm{SO}_{3}\right) \mathrm{CuPc}$ and (-4-) $\mathrm{GC} /$ MWCNT-NH $44 \beta\left(\mathrm{SO}_{3}\right) \mathrm{CuPc}$.

Figure 2 shows AFM images of the bare GC electrode (A), modified with $4 \beta\left(\mathrm{SO}_{3}\right) \mathrm{CuPc}(\mathrm{B})$ and coated with $\mathrm{MWCNT} / 4 \beta\left(\mathrm{SO}_{3}\right) \mathrm{CuPc}$. As can be observed, AFM images show the rather irregular surface of the clean GC. Adsorption of the phthalocyanine, as expected, does not alter the surface morphology, only a slight change in the appearance of a globular morphology. The height profile of the $\mathrm{GC} / 4 \beta\left(\mathrm{SO}_{3}\right) \mathrm{CuPc}$ electrode is $\sim 50 \mathrm{~nm}$ and that of the GC/MWCNT/ $4 \beta\left(\mathrm{SO}_{3}\right) \mathrm{CuPc}$ is $100 \mathrm{~nm}$.
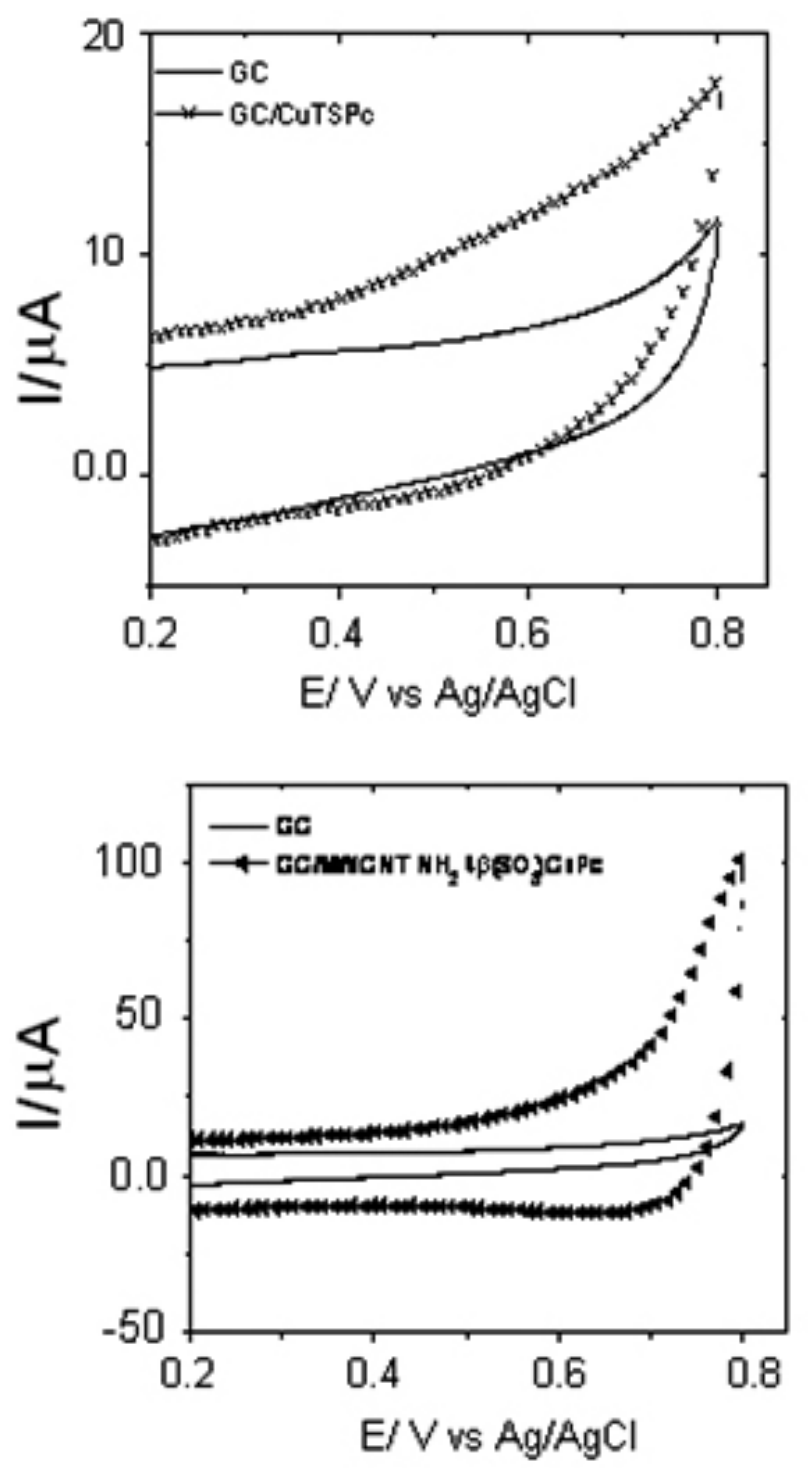

Figure 2: AFM images of the (a) GC electrode modified with of (b) $4 \beta\left(\mathrm{SO}_{3}\right) \mathrm{CuPc}$ and (c) MWCNT $4 \beta\left(\mathrm{SO}_{3}\right) \mathrm{CuPc}$.

3.2. Electrochemical behavior of dopamine without interferents.

Figure 3 shows the cyclic voltammogram obtained with a bare GC electrode for DA in PBS solution at $\mathrm{pH}$ 6.8. The first scan in the anodic direction reveals a peak at ca. $+0.15 \mathrm{~V}$ and two peaks during the cathodic scan at +0.15 and $-0.3 \mathrm{~V}$. During the second anodic scan a new peak appears at ca. -0.25 $\mathrm{V}$. The main anodic peak at +0.15 varies linearly with the potential scan rate, indicating that the oxidation of DA is controlled by mass-transport. DA oxidation produces a polymeric melanine structure which involves different steps as described by Serrano et al. ${ }^{34-40}$. First, DA is oxidized to $o$-dopaminequinone involving two protons and two electrons, followed by partial deprotonation of ethylamine group of the lateral chain. Further, $o$-dopaminequinone promotes the formation of an intermediate, which facilitates the cyclation process to form leucodopaminechrome (5,6-dihydroxi-indoline). Then, leucodopaminechrome is further oxidized to dopaminechrome, producing 5,6-dihydroxiindole, which is oxidized to indole quinine that stars the polymerization process. Concerning the cathodic process, the waves illustrated in Fig.3 are attributed to the reduction of the DA to 5,6-dihydroxyindole and aminochrome involving twoelectrons for each reduction process $\mathrm{s}^{41-46}$.

Figure 4 shows a series of cyclic voltammograms for the $1^{\text {st }}$ scan of different GC electrodes obtained in a PBS solution at $\mathrm{pH} 6.8$ and $0.244 \mathrm{mM}$ of DA. As observed in this Figure, all electrodes show oxidation and reduction peaks, for DA were enhanced considerably in the presence of MWCNT-NH $43\left(\mathrm{SO}_{3}\right)$ 
$\mathrm{CuPc}$. There is practically no shift in the oxidation potential peak of DA, so the increase in the currents can be attributed to an increment of the active area by the presence of carbon nanotubes functionalised with copper-tetrasulphonate phthalocyanine and not a catalytic effect. The GC/MWCNT-NH $4 \beta\left(\mathrm{SO}_{3}\right) \mathrm{CuPc}$ electrode was found to be stable for the detection of DA since the currents are stable after consecutive scans of the electrode in the positive direction.

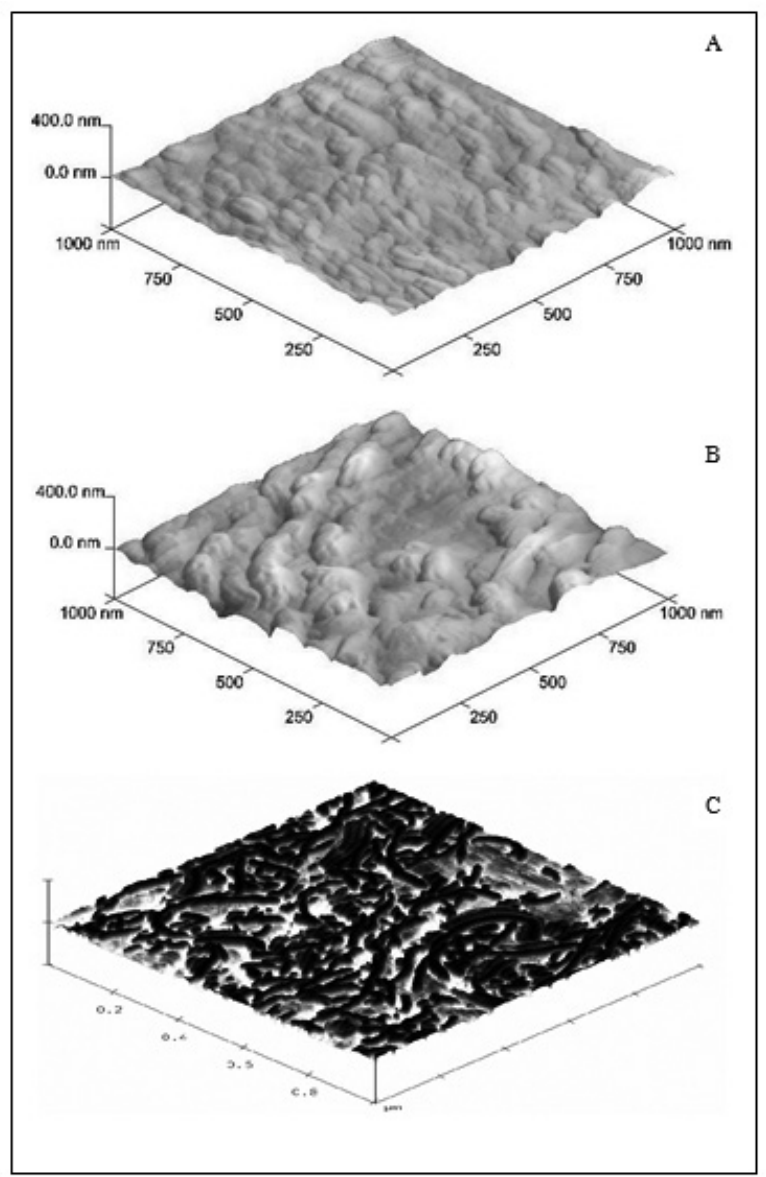

Figure 3: Cyclic voltammograms of GC electrode in a $0.1 \mathrm{M}$ PBS buffer plus $0.244 \mathrm{mM}$ DA at $\mathrm{pH}$ 6.8. (-) $1^{\text {st }}$ scan and (- - $) 2^{\text {nd }}$ scan

3.3. Electrochemical behavior of dopamine in presence of ascorbic acid and uric acid

As illustrated in Figure 5, the $4 \beta\left(\mathrm{SO}_{3}\right) \mathrm{CuPc}$ functionalized with MWCNT$\mathrm{NH}_{2}$ electrodes exhibited an significant increase in the anodic currents of DA compared to the electrode without carbon nanotubes, i.e. the $\mathrm{GC} / 4 \beta\left(\mathrm{SO}_{3}\right) \mathrm{CuPc}$ electrode. Concerning interfering, CG/MWCNTs is able to detect to AA and the hybrid electrodes shifted even the potential of anodic peak associated to the oxidation of AA is to more negative values and reveals higher anodic and cathodic currents. This effect could be associated to the increase of the active area of the hybrid electrodes due to the presence of MWCNT and the increased polarity of the $\mathrm{GC}$ electrodes modified with $4 \beta\left(\mathrm{SO}_{3}\right) \mathrm{CuPc}$ attributed to the presence of sulphonate groups on the periphery of the ligand. Thus, we were able to separate the oxidation peak potentials of the AA and UA from of the oxidation peak potential of DA.

Figure 6 a illustrates the typical CVs of GC/MWCNT-NH$/ 4 \beta\left(\mathrm{SO}_{3}\right) \mathrm{CuPc}$ electrode as a functions of scan rate. The inset illustrates the linear dependence of the anodic peak current follow an linear model such as: Ip,a DA $1^{\text {st }}$ scan $=$ $-1.19 \mathrm{E}-4+6.41 \mathrm{E}-5 \mathrm{n}^{1 / 2}$, where I is the current in $\mathrm{A}$ and $v$ is the scan rate in $\mathrm{mV}$ $\mathrm{s}^{-1}$, with $\mathrm{r}=0.9878$. For simplicity, only three cases are presented in Fig. $6 \mathrm{~b}$ illustrating the typical CVs of GC/MWCNT-NH $4 \beta\left(\mathrm{SO}_{3}\right) \mathrm{CuPc}$ electrode for concentration ranging from 0.001 to $1 \mathrm{mM}$. The inset shows that the anodic peak current as a function of DA concentration follow an exponential decay model of first-order such as: Ip, a DA $1^{\text {st }}$ scan $=1.14 \mathrm{E}-4+0.22 *[\mathrm{DA}]-50,01$ * $[\mathrm{DA}]^{2}$, where I is the current in A and [DA] is the concentration of DA in M, with $\mathrm{Ch}^{2}=9.88 \mathrm{E}^{-11}$ and $\mathrm{r}^{2}=0.99396$, if AA and UA remaining unchanged.

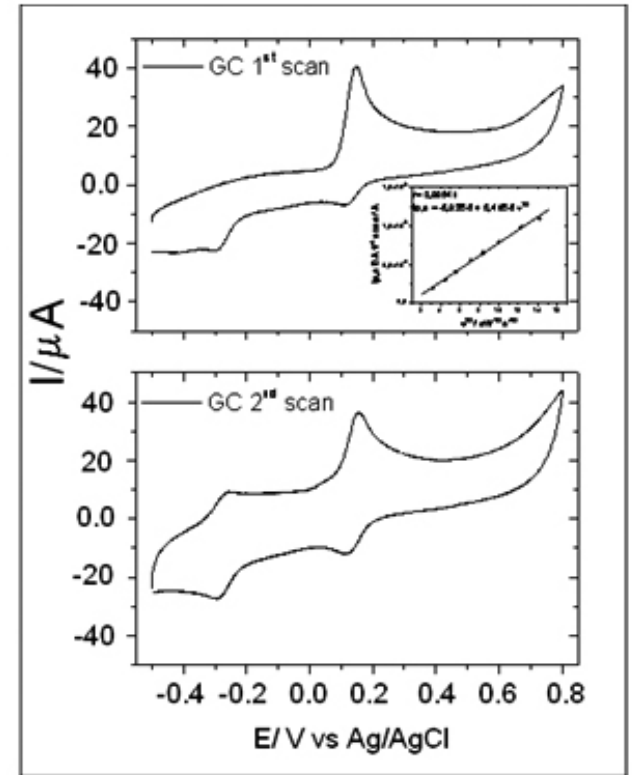

Figure 4: Cyclic voltammograms of GC electrode modified in a $0.1 \mathrm{M}$ PBS bufferplus $0.244 \mathrm{mM} \mathrm{DA}$ at $\mathrm{pH}$ 6.8. (-) GC, (-x-) $\mathrm{GC} / 4 \beta\left(\mathrm{SO}_{3}\right) \mathrm{CuPc}$ and (- - -) GC/MWCNT-NH 4 4 ( $\left(\mathrm{SO}_{3}\right) \mathrm{CuPc}$
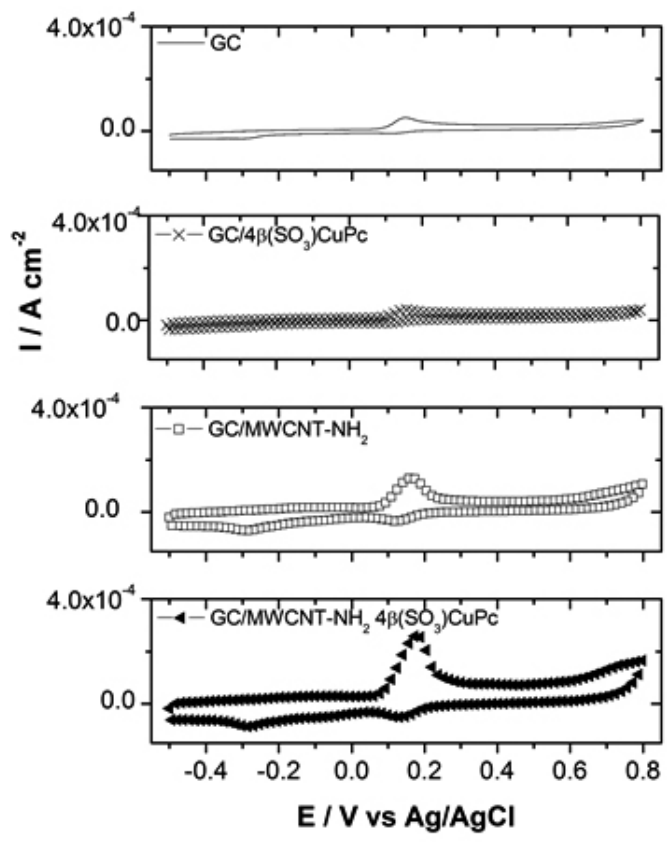

Figure 5: Cyclic voltammograms of GC electrode modified in a $0.1 \mathrm{M}$ PBS buffer at $\mathrm{pH} 6.8$ plus $0.244 \mathrm{mM}$ DA plus $2.49 \mathrm{mM}$ AA plus $2.52 \mathrm{UA} \mathrm{mM}$. Scan rate $=0.02 \mathrm{Vs}^{-1}$ and the scanning started at -0.5 to $0.8 \mathrm{~V}$ vs. $\mathrm{Ag} / \mathrm{AgCl} .(-)$ $\mathrm{GC},(-\mathrm{x}-) \mathrm{GC} / 4 \beta\left(\mathrm{SO}_{3}\right) \mathrm{CuPc},(-4-) \mathrm{GC} / \mathrm{MWCNT}-\mathrm{NH}_{2} 4 \beta\left(\mathrm{SO}_{3}\right) \mathrm{CuPc}$

In Figure 7, the electrochemical response of several $4 \beta\left(\mathrm{SO}_{3}\right) \mathrm{CMPc} / \mathrm{MW}$ CNT-NH $\mathrm{N}_{2}$ electrodes is compared, to show the effect of the central metal $(\mathrm{M}=$ $\mathrm{Fe}, \mathrm{Ni}, \mathrm{Cu}$ and $\mathrm{Zn}$ ). Measurements were conducted with DA in the presence of interferents AA and UA and it can be seen that the Co complex shows a better separation of the signals. The copper complex show a response somewhat similar to the Ni complex but the worse and less discriminating response corresponds to the Fe complxes, which shows a pre-wave attributed to the oxidation of AA not shown by the other metal chelates. This justifies the use of a copper complex for these measurements. 

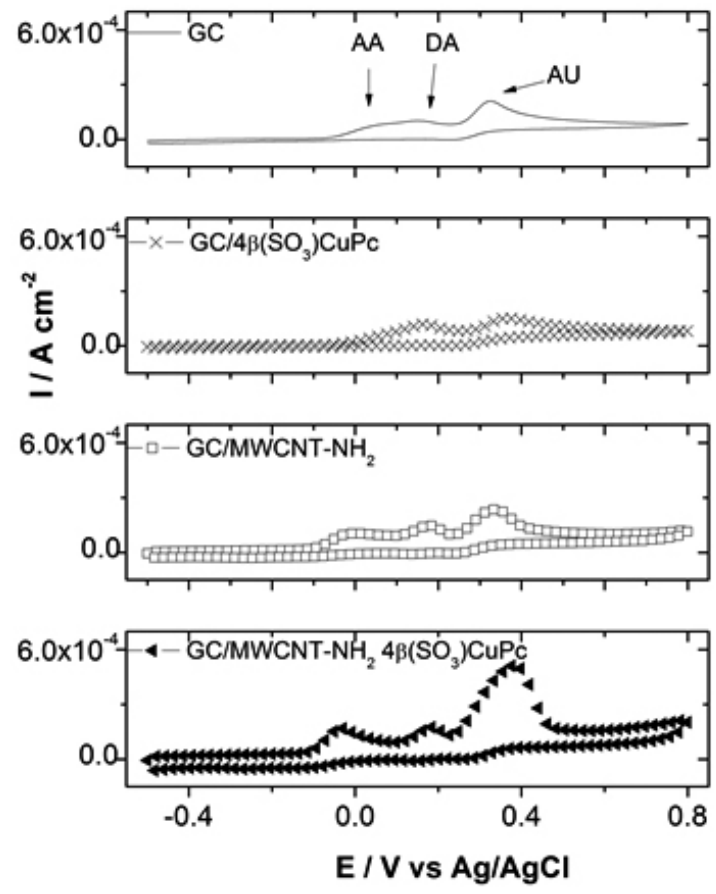

Figure 6: Cyclic voltammograms of GC electrode modified in a $0.1 \mathrm{M}$ PBS buffer at $\mathrm{pH} 6.8$ plus $0.244 \mathrm{mM}$ DA plus $2.49 \mathrm{mM}$ AA plus $2.52 \mathrm{mM} \mathrm{UA}$ as a function of (a) scan rate and (b) concentration of DA.
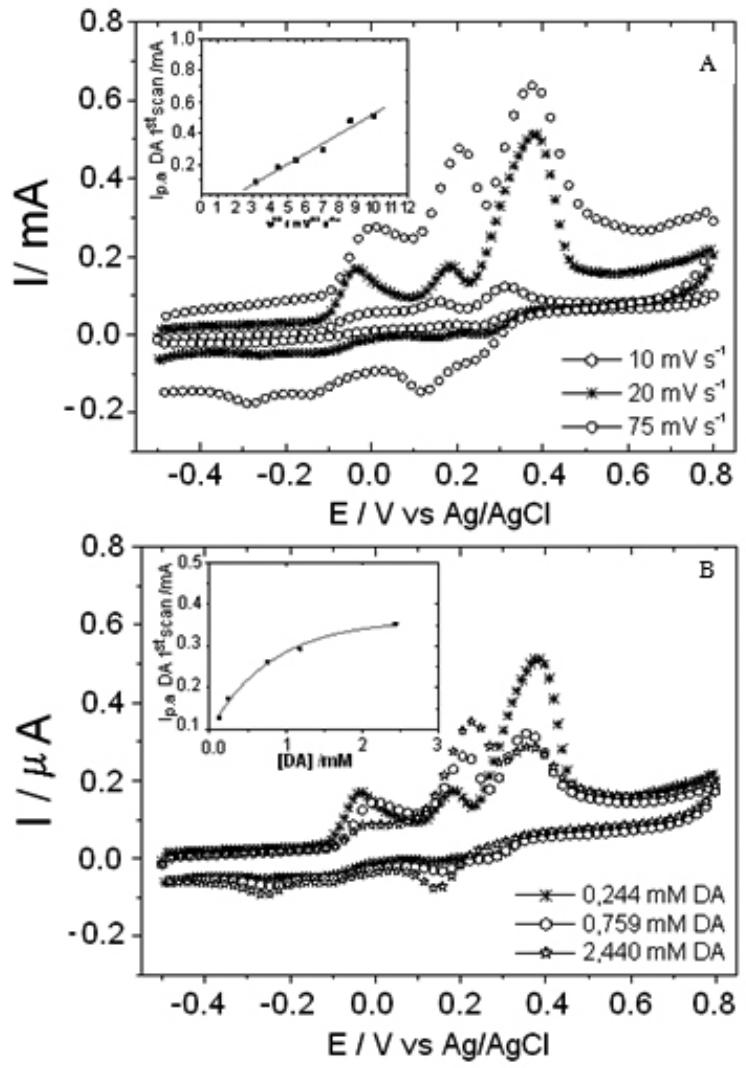

Figure 7: Cyclic voltammograms of a $\mathrm{GC}$ electrode modified with $4 \mathrm{~B}_{\left(\mathrm{SO}_{3}\right)}$ $\mathrm{MPc}$ where $\mathrm{M}$ is $\mathrm{Fe}, \mathrm{Ni}, \mathrm{Cu}$ and $\mathrm{Zn}$ in a $0.1 \mathrm{M}$ PBS buffer at $\mathrm{pH} 6.8$ plus 0.244 mM DA plus 2.49 mM AA plus 2.52 mM UA.

\section{CONCLUSIONS}

The main conclusion of this work is that the presence of $\mathrm{Cu}$ sulphonated phthtalocyanine on multiwalled carbon nanotubes on the electrode surface does not catalyze the anodic oxidation of the target molecule DA but increases the resolution of the response of the electrode in the presence of interferents AA and UA. When comparing sulphonated phthalocyanines of different metals, the $\mathrm{Cu}$ derivative shows better peak resolution for the response of DA in the presence of AA and UA with the Fe complex showing the worse response. The separation between the anodic potentials of AA and DA and UA is much higher with copper-tetrasulphonate phthalocyanine functionalized with MWCNT, which is adequate for a selective sensor development of these three substances and can represent an attractive and efficient tool for analysis of DA in a simple, fast and low-cost fashion.

\section{ACKNOWLEDGEMENTS}

This work was supported by Fondecyt Projects 1100773, 11100450 and 3095011, Millennium Nucleus of Molecular Engineering for Catalysis and Biosensors and by Dicyt USACH.

\section{REFERENCES}

1. Y. Chen, L.R. Guo, W. Chen, X.J Yang, B.J., L.M. Zheng, X.H. Xia, Bioelectrochemistry. 75, 26, (2009)

2. P.E.M. Phillips, G.D. Stuber, M.L.A.V. Heien, R.M. Wightman, R.M. Carelli, Nature. 422, 614, (2003)

3. A.A. Grace, Neuroscience.41, 1, (1991)

4. D.R. Weinberger, B.K. Lipska, Schizophr. Res. 16, 87, (1995)

5. A. Hermans, A.T. Seipel, Ch. E. Miller and R. Mark Wightman, Langmuir.22, 1964, (2006)

6. C.Y. Hsu, V.S. Vasantha, P.Y. Chen, K. Ch. Ho, Sensors and Actuators B. 137, 313, (2009)

7. W. Yeh, Y. Kuo, S. Cheng, Electrochem. Commun. 10, 66, (2008)

8. Z. Jia, J. Liu, Y. Shen, Electrochem. Commun.9, 2739, (2007)

9. N. Jia, Z. Wang, G. Yang, H. Shen, L. Zhu, Electrochem. Commun.9, 233, (2007)

10. Y. Wang, Y. Li, L. Tang, J. Lu, J. Li, Electrochem. Commun.11, 889, (2009)

11. R. Zhang, G.D. Jin, D. Chen, X.Y. Hu, Sensors and Actuators B. 13, 174, (2009)

12. I.L. Mattos, F. Padilla, J. H. Zagal, E.H.L. Falcao, R. Segura, J. Chil. Chem. Soc., 56, 803 (2011)

13. L. J. May, W. Kuhr, R. M. Wightman, J. Neurochem.51, 1060, (1988)

14. J. Zen and I. Lang Chen, Electroanalysis, 9, 537, (1997)

15. J. Huang, Y. Liu, H. Hou, T. You, Biosensors and Bioelectronics. 24, 632, (2008)

16. G.-S. Lai, H.-L. Zhang, D.-Y. Han, Microchim. Acta, 160, 233, (2008)

17. F. Terzi, C. Zanardi, V. Martina, L. Pigani, R. Seeber, J. Electroanal. Chem. 619, 75, (2008)

18. Z. Gao, H. Huang, Chem. Commun. 2107, (1998)

19. B.B. Prasad, S. Srivastava, K. Tiwari, P.S. Sharma, Biochemical Engineering Journal, 44, 232, (2009)

20. D. Lakshmi, A. Bossi, M.J. Whitcombe, I. Chianella, S.A. Fowler, S. Subrahmanyam, E.V. Piletska, and S.A. Piletsky, Anal. Chem. 81, 3576, (2009)

21. D. Hemández-Santos, M.B. González-García, A.C. García, Electroanalysis. 14, 1225, (2002)

22. E. Katz, I. Willner, J. Wang, Electroanalysis. 16, 19, (2004)

23. J. Huang, Y. Liu, H. Hou, T. You, Biosensors and Bioelectronics. 24, 632, (2008)

24. S.B. Hočevar, J. Wang, R.P. Deo, M. Musameh, B. Ogorevc, Electroanalysis. 17,417, (2005)

25. Y. Liu, J. Huang, H. Hou, T. You, Electrochem.Commun. 10, 1431, (2008)

26. J. Oni, T. Nyokong, Polyhedron. 19, 1355, (2000)

27. T.F. Kang, L.G. Shen, R.Q. Yu, Anal. Chim. Acta. 356, 245, (1997)

28. A. Porras-Gutierrez, M. Rangel-Argote, S. Griveau, J. H. Zagal, S. Gutierrez-Granados, A. Alatorre-Ordaz, F.Bedioui, J. Chil. Chem.Soc. 57, 1244 (2012)

29. J.H. Zagal, S. Griveau, J. F. Silva, T. Nyokong, F. Bedioui, Coord. Chem. Revs. 254, 2755, (2010)

30. J. H. Zagal, S. Griveau, M. Santander-Nelli, S. Gutierrez-Granados, 
F.Bedioui. J. Porphyrins Phthalocyanines 16, 28, (2012).

31. A. Alatorre Ordaz, F. Bedioui, S. Gutierrez Granados. Bol. Soc. Chil. Quim., 43375 (1998).

32. N. Sehloto, T. Nyokong, J.H. Zagal, F. Bedioui, Electrochim. Act,a $\mathbf{5 1 , 5 1 2 5 ( 2 0 0 6 )}$

33. J.H.Zagal, J.J.H. Henriquez, Bol. Soc. Chil. Quim., 45, 237 (2000)

34. G.I. Cardenas-Jiron, J.H. Zagal J. Electroanal. Chem., 497, 55 (2001)

35. C.A.Caro, F.Bedioui, M.A.Páez, G.I.Cardenas-Jiron, J.H. Zagal, J. Electrochem. Soc.,151, E-32 (2004)

36. M.S.Ureta-Zañartu, M.S.Alarcon, C. Berrios, G.I. Cárdenas-Jirón, J.H. Zagal, J. Electroanal. Chem., 580, 94 (2005)

37. T. Wossmeyer, B. Guse, I. Besnard, R.E. Bauer, K. Müllen, A. Yasuda, Adv. Mater.,14, 238, (2002)

38. V. Zucolotto, M. Ferreira, M.R. Cordeiro, C.J.L. Constantino, D.T. Balogh, A.R. Zanatta, W.C. Moreira and O.N. Oliveira Jr., J. Phys. Chem. B. 107, 3733, (2003)
39. D. Geraldo, C. Linares, Y.Y. Chen, S. Ureta-Zañartu, J.H. Zagal, Electrochem. Comm., 4, 182, (2002)

40. R.P. da Silva, A. William O. Lima, S.H.P. Serrano, Anal. Chim. Acta, 612, 89, (2008)

41. T.E. Young, B.W. Babbit, J. Org. Chem., 48, 562, (1983)

42. F. Zhang, G. Dryhurst, J. Electroanal. Chem., 398, 117, (1995)

43. M.D. Hawley, S.V. Tatawawadi, S. Piekarski, R.N. Adams, J. Am. Chem. Soc., 89, 447, (1967)

44. J. Oni and T. Nyokong, Anal. Chim. Acta, 434, 9, (2001)

45. P. Manini, L. Panzella, A. Napolitano and M. d'Ischia, Tetrahedron, 59, 2215, (2003)

46. P. Manini, A. Pezzella, L. Panzella A. Napolitano and M. d'Ischia, Tetrahedron, 61, 4075, (2005) 